\title{
Visual Outcome of Combined Descemet Stripping Endothelial Keratoplasty and Sutured Scleral Fixated Intraocular Lens in Endothelial Decompensation with Coexistent Aphakia or Intra Ocular Lens Subluxation
}

\author{
Jaya Kaushik ${ }^{1, \odot ~ A n k i t a ~ S i n g h ~}{ }^{1}$ Rakesh Shetty ${ }^{1}$ Jitendra Kumar Singh Parihar ${ }^{2}$ \\ Divya Kochhar ${ }^{1} \quad$ Aanchal Singhal $^{1}$
}

${ }^{1}$ Department of Ophthalmology, Armed Forces Medical College, Pune, Maharashtra, India

2Glaucoma Unit, Centre for Sight, New Delhi, India

Address for correspondence Jaya Kaushik, MBBS, MS, DNB, Department of Ophthalmology, Armed Forces Medical College, Pune 411040, Maharashtra, India (e-mail: arnavjaya@gmail.com).

Ann Natl Acad Med Sci (India) 2021;57:220-225.

\begin{abstract}
Purpose To elucidate visual outcome of patients after combined Descemet stripping endothelial keratoplasty (DSEK) with scleral fixated intra ocular lens (SFIOL) implantation in patients of endothelial decompensation with coexistent aphakia or lens subluxation.

Materials and Methods A prospective interventional study of combined DSEK with sutured SFIOL in the patients who have undergone surgery at our center over 6-month follow-up period. Preoperative visual acuity and slit lamp findings were documented. Postoperative follow-up was done at days 1,3 , and 7 subsequently, months 1 and 3 , and thereafter monthly till the sixth month.

Results Mean age of the patients was 60.47 years. Six patients had aphakic bullous keratopathy, while 11 patients had pseudophakic bullous keratopathy with subluxated posterior chamber IOL (PCIOL). Preoperative visual acuity ranged from hand movements close to face (LogMar 2.4) with accurate projection of rays to $1 / 60$ (LogMar 2) due to existing corneal edema and aphakia. Postoperatively uncorrected visual acuity

Keywords

- endothelial keratoplasty

- endothelial keratoplasty with SFIOL

- SFIOL at 6 months improved up to 6/36 (LogMar 0.8) in all cases. There was gradual improvement in corneal clarity and compactness during the follow-up. A good donor tissue endothelial count and an adequate IOP control were vital prognostic factors for the successful outcome.

Conclusion This novel surgical merger reduces the complications of lenticule dislocation into vitreous and repeated surgeries and shows results akin to when performed in a staged manner.
\end{abstract}

\section{Introduction}

Bullous keratopathy, an important complication of cataract surgery, especially those involving anterior chamber intra ocular lens (ACIOL) implantation, entails keratopathy consequent to endothelial dysfunction and resultant corneal blindness.

published online October 26, 2021
DOI https://doi.org/

$10.1055 / \mathrm{s}-0041-1739036$ ISSN 0379-038X
At present, Descemet stripping endothelial keratoplasty (DSEK) is the procedure of choice to manage endothelial dysfunction, especially aphakic/pseudophakic bullous keratopathy and involves selective replacement of the diseased endothelium with healthy donor lenticule. ${ }^{1,2}$ Contrary to the conventional full thickness keratoplasty, this surgery

\section{(C) 2021. National Academy of Medical Sciences (India).}

This is an open access article published by Thieme under the terms of the Creative Commons Attribution-NonDerivative-NonCommercial-License, permitting copying and reproduction so long as the original work is given appropriate credit. Contents may not be used for commercial purposes, or adapted, remixed, transformed or built upon. (https://creativecommons.org/licenses/by-nc-nd/4.0/).

Thieme Medical and Scientific Publishers Pvt. Ltd. A-12, 2nd Floor, Sector 2, Noida-201301 UP, India 
has a significant advantage in terms of increased wound stability, lesser postoperative astigmatism, and a rapid recovery. ${ }^{2}$ Various studies have suggested that aphakic and pseudophakic bullous keratopathy amount for nearly $40 \%$ of keratoplasties in the current scenario.,4 However, visual rehabilitation utilizing DSEK in bullous keratopathy following surgical aphakia or subluxated IOL is challenging, especially in those with deficient posterior capsule, as there increased risk of posterior migration of injected air and dislocation of lenticule into vitreous cavity. ${ }^{5,6}$ There have been different schools of thought for IOL implantation during endothelial keratoplasty in aphakia. The viable options as per different studies reveal either to remove dislocated IOL during keratoplasty, rendering eye aphakic, and performing secondary IOL implantation or removing old dislocated IOL in exchange for a new IOL implantation..$^{6-9}$ As the realm of DSEK continues to increase, concerted approach of scleral fixated IOL (SFIOL) implantation with DSEK in the same surgical setting in patients of corneal decompensation with subluxated IOL or aphakia owing to various etiologies is gaining enormous interest, as it provides a better visual rehabilitation to these patients minimizing repeated surgeries, lenticule drop rate in aphakia, and incidence of secondary glaucoma. In this article, we have highlighted the successful visual rehabilitation in patients of corneal decompensation with aphakia or subluxated IOL who have undergone DSEK with SFIOL implantation in the same surgical setup.

\section{Materials and Methods}

A prospective interventional study was conducted at our center, taking into account all those patients who were clinically diagnosed to have corneal decompensation with aphakia/subluxated posterior chamber IOL owing to various etiologies and were planned to undergo this novel technique of combined DSEK with SFIOL implantation in the same surgical sitting. The study duration was 6 months and written informed consent for the same was obtained from the patients before including them in the study. The study was

Table 1 Demographic profile of the patients

\begin{tabular}{|c|c|c|}
\hline \multicolumn{2}{|c|}{ Demographic characteristics } & Value/Number of patients \\
\hline \multicolumn{2}{|c|}{ Total no of patients } & 17 \\
\hline \multicolumn{2}{|c|}{ Age (y) Mean } & 60.47 \\
\hline \multirow[t]{2}{*}{ Sex } & Male & 10 \\
\hline & Female & 07 \\
\hline \multirow[t]{3}{*}{ Age group (y) } & $\leq 40$ & $01(5.9 \%)$ \\
\hline & $41-60$ & $05(29.4 \%)$ \\
\hline & $>60$ & $11(64.7 \%)$ \\
\hline \multirow{2}{*}{$\begin{array}{l}\text { Indications } \\
\text { for DSEK with } \\
\text { SFIOL }\end{array}$} & ABK & 06 (35.29\%) \\
\hline & $\begin{array}{l}\text { PBK with } \\
\text { subluxated } \\
\text { PCIOL }\end{array}$ & $11(64.71 \%)$ \\
\hline
\end{tabular}

Abbreviations: ABK, aphakic bullous keratopathy; DSEK, Descemet stripping endothelial keratoplasty; PBK, pseudophakic bullous keratopathy; PCIOL, posterior chamber intraocular lens; PK, penetrating keratoplasty; SFIOL, scleral fixated intra ocular lens. approved by the local ethics committee and adheres to the Declaration of Helsinki. To avoid the potentially confounding effects of adverse visual outcomes of complicated cases, viz., advanced subepithelial fibrosis in cases with aphakic or pseudophakic bullous keratopathy, cystoid macular edema, corneal scarring, or history suggestive of prolonged postoperative intraocular inflammation, and others, careful patient selection was done to include uncomplicated cases of corneal endothelial decompensation without posterior capsular support but with no vitreous prolapse into anterior chamber. Furthermore, anticipating corneal endothelial compromise as a consequence of the prolonged period of surgery and resultant ocular insult, high optical grade donor cornea with good endothelial count was used to ensure favorable visual prognosis. A total of 17 patients (-Table 1 ) were followed-up during this period including 10 males and 7 females with a mean age of 60.47 years. The patients underwent complete ocular examination, including preoperative slit lamp examination, refraction, baseline visual acuity assessment using Snellen's chart and IOP measurement by Goldman Applanation Tonometry (-Table 2). Subsequently, each patient was subjected to anterior segment optical coherence tomography and ultrasonography B Scan to evaluate the thickness of cornea and rule out any retinal pathology. Patients having CME or any retinal pathology were excluded. Slit lamp photographs of the patients were taken to document the findings (-Fig. 1). The patients were explained adequately about the surgical procedure and the written, informed consent was taken individually from all the patients, prior to surgery, to use the data for the study purpose. All patients were closely followed-up at regular intervals postoperatively to assess the outcome of surgery on day 1 and 7, weeks 4 and 12, and then every monthly for the 6-month study period. The parameters assessed were graft survival and clarity, stability of SFIOL, and unaided visual acuity. All patients had a preoperative corneal clarity grade $1+.^{10}$ Serial photographs on anterior segment imaging system were also taken to record the outcome of the surgery. Patients were also evaluated explicitly to rule out any complication following surgery.

\section{Surgical Steps}

All the patients were operated by a single surgeon under peribulbar anesthesia. Written, informed consent was taken from the patients and relatives, before the surgery.

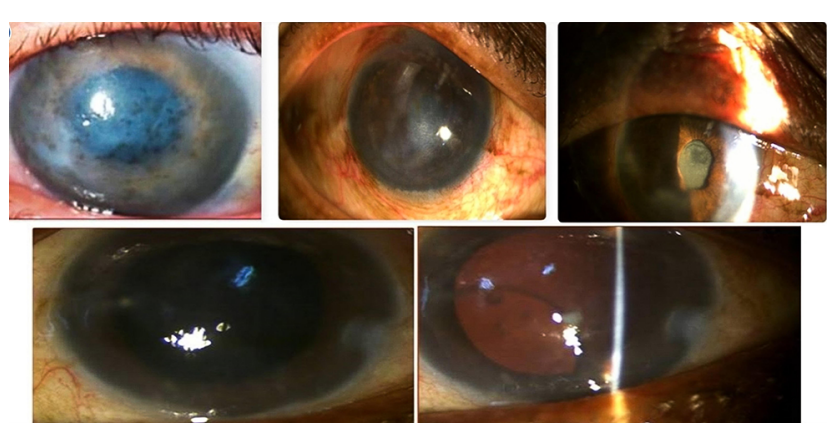

Fig. 1 Preoperative slit lamp pictures of patients with who underwent combined DSEK with SFIOL. DSEK, Descemet stripping endothelial keratoplasty; SFIOL, scleral fixated intra ocular lens. 
Table 2 Descriptive statistics of visual acuity in the operated patients (in LogMar)

\begin{tabular}{|l|l|l|l|l|l|l|l|}
\hline \multirow{2}{*}{$\begin{array}{l}\text { Vision in } \\
\text { LogMar at }\end{array}$} & \multirow{2}{*}{$\begin{array}{l}\text { Number of } \\
\text { patients }\end{array}$} & \multicolumn{9}{|c|}{ Vision in LogMar } & \multirow{2}{*}{-Value } \\
\cline { 3 - 8 } & & Minimum & Maximum & Mean & SD & Median \\
\hline Preoperative & 17 & 2 & 2.9 & 2.37 & 0.37 & 2.4 & \\
\hline Day 1 & 17 & 2 & 2.4 & 2.24 & 0.20 & 2.4 & $<0.001$ \\
\hline Day 3 & 17 & 1.8 & 2.4 & 2.04 & 0.28 & 1.9 & $<0.001$ \\
\hline Day 7 & 17 & 1.8 & 2 & 1.89 & 0.09 & 1.9 & $<0.001$ \\
\hline 1 month & 17 & 1.17 & 1.8 & 1.43 & 0.20 & 1.3 & $<0.001$ \\
\hline 3 months & 17 & 1 & 1.17 & 1.05 & 0.07 & 1 & $<0.001$ \\
\hline 6 months & 17 & 0.6 & 1 & 0.72 & 0.13 & 0.77 & $<0.001$ \\
\hline
\end{tabular}

Abbreviation: SD, standard deviation.

Note: $p$-Value $<0.05$ (significant). Paired $t$-test is used.

The patients underwent scleral fixated IOL implantation and DSEK, concurrently (-Fig. 2). Overlying hyperplastic and edematous corneal epithelium was debrided to enable clear visualization of the anterior chamber (-Fig. 2A). Conjunctival peritomy was done from 3 to 9 o'clock for 180 degrees. Adequate hemostasis was obtained by using wet field cautery. Two partial thickness scleral tunnels of size $1.5 \mathrm{~mm}$ were created $2 \mathrm{~mm}$ from the limbus at 3 and 9 o'clock (-Fig. 2B). Main incision of $5.5 \mathrm{~mm}$ was made superiorly at limbus by keratome. In cases with subluxated IOLs, removal of the IOL was done after appropriate intraocular maneuvering, via the main incision, followed by adequate anterior vitrectomy using $23-\mathrm{G}$ vitrectomy probe. To fixate the SFIOL, 10-0 polypropylene suture with straight needle was inserted from one tunnel first and taken out from the main incision with the help of a bent $26-G$ needle. The suture was then threaded through the eyelet of the $6-\mathrm{mm}$ poly methyl methacrylate SFIOL thrice to secure the SFIOL (-Fig. 2C). Thereafter, the needle was passed through the main port to come out of the same tunnel with the help of 26-G needle. The same procedure was then performed on the other side. The rigid PMMA SFIOL was introduced into the sulcus with a McPherson forceps after safely securing the haptic eyelet with 10-0 polypropylene suture at both ends.
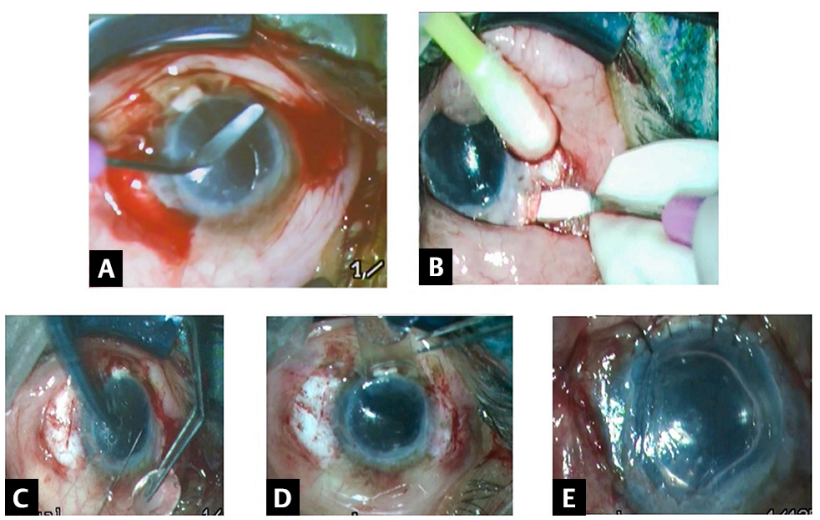

Fig. 2 [SB10]Steps of the surgical technique (A) epithelium debridement followed by 180-degree conjunctival peritomy (B) Scleral tunnel being made. (C) Polypropylene suture inserted into eyelet of SFIOL haptic (D) Lenticule being inserted through sheet glide (E) Well adhered lenticule post air tamponade with SFIOL in situ. SFIOL, scleral fixated intra ocular lens.
The sutures were tied and the knots were buried in scleral tunnel on both the sides. The donor lenticule dissection was performed on an artificial anterior chamber before commencing the surgery. The anterior lamellar dissection up to pre-Descemet level was done. The recipient bed was marked with an $8-\mathrm{mm}$ trephine following which Descemet membrane scoring was performed using a reverse Sinskey's hook. An 8-mm trephine was used to attain the appropriately sized donor corneal button and the endothelial side was marked. The lenticule was placed over the sheet glide ( - Fig. 2D) with Healon GV and inserted into the anterior chamber using a bent 26-G needle (cystitome). The sheet glide was then removed and air tamponade was done to ensure adherence of donor lenticule to host stroma (-Fig. 2E). The incision was closed using 10-0 monofilament nylon sutures. And conjunctiva reposed back. Postoperatively, they were managed with tapering doses of topical steroids (prednisolone 1\%), topical antibiotics (moxifloxacin 0.5\%), and topical lubrication (hydroxypropyl methyl cellulose 0.3\%). Postoperatively, strict supine position was observed for the first 24 hours by the patients. Graft dislocation was seen in two patients on first postoperative day who were then taken up for rebubbling and had successful graft attachment subsequently.

\section{Statistical Analysis}

Data analysis was performed by using SPSS (Statistical Package for social sciences) Version 25:0. Quantitative data variables have been expressed as mean and standard deviation, qualitative data variables have been expressed by using frequency and percentage (\%). Paired $t$-test has been used to compare mean uncorrected visual acuity (LogMar) at preand postoperative follow-ups. Wilcoxon's sign rank test has been used to compare the central corneal thickness (CCT) and corneal clarity grade at pre- and postoperative follow-ups. The $p$-value of $<0.05$ has been considered as significant for this study.

\section{Results}

This study included 17 patients (17 eyes) and the study duration was 6 months. The mean age of the 10 males (59\%) and 7 females (41\%) was 60.47 years (range: $34-78$ years). Combined DSEK with SFIOL was performed successfully in all 
the eyes. Of these, 6 eyes had aphakic bullous keratopathy while the remaining 11 eyes had pseudophakic bullous keratopathy with subluxated PCIOL. The mean uncorrected distance visual acuity significantly improved in all these patients from preoperative 2.37 (LogMar) to postoperative 0.72 (LogMar). After, 6-month postoperative period, follow-up patients had well-centered SFIOL in situ, clear cornea (corneal clarity grading $3+$ to $4{ }^{+10}$ ) with DSEK lenticule well apposed to graft host junction and fundus examination revealed healthy optic disc and macula ( - Fig. 3 ). The mean CCT reduced from 778.35 to $530.59 \mu \mathrm{m}$ after 6 months of follow-up (-Table 3 ). The mean endothelial cell density was 2,942 cells $/ \mathrm{mm}^{2}$ in donors (range: $2,716-3,214$ cells $/ \mathrm{mm}^{2}$ ) in donors and 1,844 cells $/ \mathrm{mm}^{2}$ (range: $1,644-2,171$ cells $/ \mathrm{mm}^{2}$ ) in recipient patients. Endothelial cell loss was $37 \%$ at 6 -month follow-up. There were no instances of graft infection, rejection or incarceration, and SFIOL subluxation or haptic extrusion after the follow-up period of 6 months.

\section{Discussion}

Bullous keratopathy is characterized by corneal stromal edema with epithelial or subepithelial bullae due to cell loss and endothelial decompensation. In more advanced cases, subepithelial fibrosis, formation of a posterior collagenous layer or retrocorneal fibrous membrane, and corneal vascularization can occur leading to loss of corneal transparency. The main etiology is the endothelial cell loss after ophthalmic

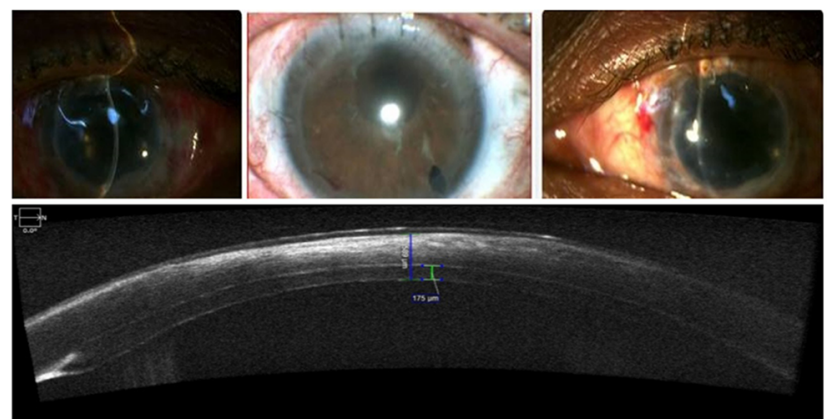

Fig. 3 Post-operative slit lamp image of a patient with ASOCT image of well adhered DSEK lenticule. DSEK, Descemet stripping endothelial keratoplasty. surgeries such as cataract surgery. ${ }^{11}$ Cataract affects approximately 100 million people worldwide, and this complication can occur in 1 to $2 \%$ of cataract surgeries. ${ }^{12,13}$ In the current scenario, DSEK has largely replaced penetrating keratoplasty (PK) in the management of endothelial disorders such as aphakic and pseudophakic bullous keratopathy. ${ }^{14}$ Currently, bullous keratopathy is among the most common indications for DSEK and regraft. ${ }^{13,15-19}$ Complications of DSEK surgery include graft dislocations, pupillary block, endothelial cell loss, primary graft failure, all of which can be minimized with proper patient selection and employment of better surgical techniques., ${ }^{2,6,9,20-24}$ Surgical management of aphakic bullous keratopathy or pseudophakic bullous keratopathy involves replacement of the diseased cornea with additional requirement of an IOL placement or exchange procedure. ${ }^{6}$ These two vital surgical procedures can be done concurrently as a concerted approach or as a staged procedure. So the question then arises as to whether IOL implantation or exchange needs to be done with DSEK surgery as a separate procedure or whether the two procedures can be safely combined into a single sitting without the risk of aggravating additional endothelial cell loss and other complications associated with DSEK alone. The mean ECD in this study was 2,942 cells $/ \mathrm{mm}^{2}$ in donors (range: $2,716-3,214$ cells $/ \mathrm{mm}^{2}$ ) in donors and 1,844 cells $/ \mathrm{mm}^{2}$ (range: $1,644-2,171$ cells $/ \mathrm{mm}^{2}$ ) in recipient patients. Endothelial cell loss was $37 \%$ at 6 -month follow-up which comparable to the rate of endothelial cell loss associated with routine DSEK surgery..$^{21,25}$ The few studies available on the subject ${ }^{8,9,20}$ also report that endothelial cell loss and complications associated with DSEK combined with IOL exchange or are comparable to their incidences with DSEK alone. Hence, the two surgeries can be done in a single sitting, reducing the number of surgeries. Due to absence of capsular bag support in aphakic bullous keratopathy, the options are limited and include ACIOLs, iris claw lenses and trans-SFIOLs. ${ }^{6,8,20,26-28}$ In cases of pseudophakic bullous keratopathy (PBK), the IOL is not appropriately placed in some cases and may require removal, replacement, or repositioning. Intraocular lens exchange is recommended in cases with closed-loop IOLs, semiflexible ACIOLs, iris-supported IOLs, or unstable IOLs because these IOLs have been increasingly associated with endothelial compromise and poor macular function postoperatively. ${ }^{6}$ As all

Table 3 Mean change in central corneal thickness of the patients on follow up

\begin{tabular}{|l|l|l|l|l|l|l|l|}
\hline \multirow{2}{*}{ CCT } & \multirow{2}{*}{$\begin{array}{l}\text { Number of } \\
\text { patients }\end{array}$} & \multicolumn{3}{|c|}{ CCT } & \multirow{2}{*}{$p$-Value } \\
\cline { 3 - 8 } & & Minimum & Maximum & Mean & SD & Median \\
\hline Preoperative & 17 & 668 & 896 & 778.35 & 68.03 & 789 & \\
\hline Day 1 & 17 & 660 & 893 & 778.18 & 67.29 & 788 & 0.868 \\
\hline Day 3 & 17 & 634 & 881 & 744.24 & 71.74 & 740 & $<0.001$ \\
\hline Day 7 & 17 & 602 & 791 & 698.41 & 46.96 & 704 & $<0.001$ \\
\hline 1 month & 17 & 580 & 692 & 636.35 & 36.61 & 634 & $<0.001$ \\
\hline 3 months & 17 & 525 & 614 & 567.18 & 30.97 & 567 & $<0.001$ \\
\hline 6 months & 17 & 490 & 633 & 530.59 & 39.26 & 514 & $<0.001$ \\
\hline
\end{tabular}

Abbreviations: CCT, central corneal thickness; SD, standard deviation.

Note: $p$-Value $<0.05$ (significant). Wilcoxon's sign rank test is used. 
cases in our series had compromised capsule support, SFIOL was a viable option. ${ }^{26,27,29,30}$ Because of its anatomic location, SFIOLs also have the advantage of not reducing anterior chamber volume or the requirement of intact iris tissue making them more appropriate for eyes with compromised cornea, peripheral anterior synechiae, shallow anterior chamber, or glaucoma. ${ }^{26}$ ACIOLs are the culprit for the corneal decompensation, can cause significant damage to angle structures leading to dreaded complication of secondary glaucoma, postoperative chronic uveitis, and hyphaema, ${ }^{31}$ whereas iris claw lenses require intact iris, hence cannot be placed in cases of deficient iris. ${ }^{8}$ Also, they can cause endothelial damage, although the destruction to angle structures are not seen and reported. So, the better option in these cases remains SFIOLs which can be further be either sutured or glue fixated. ${ }^{6,20}$ In our study, patients underwent implantation of transscerally sutured SFIOL followed by the standard DSEK procedure ${ }^{1,2,14,23,24,32-34}$ in one sitting. Both sutured and sutureless glue-fixated SFIOLs have been reported to be equally good as means of IOL implantation or exchange. ${ }^{35,36}$ and sutured SFIOL was used in this study merely for its cost-effectiveness, although as compared with sutureless IOLs, sutured SFIOLs are preferred for large myopic eye with large limbus to limbus diameter as also for post trauma eyes with significant corneoscleral and conjunctival scarring at limbus. ${ }^{35}$ While SFIOLs are reported to be associated with complications, like retinal detachments, cystoid macular edema, hypotony, secondary glaucoma, hyphema, vitreous hemorrhage, and lens decentration, their incidences has come down considerably with better surgical and postoperative care techniques being employed lately. ${ }^{7,27,35,37-39}$ The mean uncorrected distance visual acuity significantly improved in all these patients from preoperative 2.37 (LogMar) to postoperative 0.72 (LogMar). After 6 months of postoperative follow-up, patients had well centered SFIOL in situ, clear cornea with DSEK lenticule well apposed to graft host junction, and fundus examination revealing a healthy optic disc and macula. Furthermore, instances of graft infection or rejection, SFIOL subluxation, and haptic extrusion were not noted. The excellent graft survival, in our study of combined DSEK with IOL exchange, emphasizes that when careful case selection and deliberate measures to ensure a quiet eye, with no or minimal risk factors for corneal endothelial decompensation before planning for surgery, is combined with use of high optical grade corneal lenticule with good endothelial count, the chances of success are vastly increased and this extensive procedure need not be staged into two surgeries to enhance graft viability.

\section{Conclusion}

Concurrent DSEK with scleral fixated IOL implantation is a viable option in patients with aphakic/pseudophakic bullous keratopathy with subluxated IOL and absent or dehiscent capsular support does not seem to be associated any increased incidence of endothelial cell or other complications as would be found when the two procedures are performed in a staged manner. This novel surgical merger reduces the complications of lenticule dislocation into vitreous and repeated surgeries. However, a large-scale randomized control trial should be done to elucidate the long-term effects of this surgical merger.

\section{Note}

Written informed consent was obtained.

\section{Conflict of Interest}

None declared.

\section{References}

1 Gorovoy MS. Descemet-stripping automated endothelial keratoplasty. Cornea 2006;25(8):886-889

2 Terry MA, Ousley PJ. Deep lamellar endothelial keratoplasty. Ophthalmology 2005;112(9):1541-1548

3 Nishiwaki-dantas MC, Abbott RL, Webster RG, Fung WE. Penetrating keratoplasty and anterior chamber intraocular lens implant: outcomes in aphakic and pseudophakic bullous keratopathy. Arch Ophthalmol 1997;60(5):542-545

4 Smith PW, Wong SK, Stark WJ, Gottsch JD, Terry AC, Bonham RD. Complications of semiflexible, closed-loop anterior chamber intraocular lenses. Arch Ophthalmol 1987;105(1)52-57

5 Suh LH, Kymionis GD, Culbertson WW, O'Brien TP, Yoo SH. Descemet stripping with endothelial keratoplasty in aphakic eyes. Arch Ophthalmol 2008;126(2):268-270

6 Sinha R, Shekhar H, Sharma N, Tandon R, Titiyal JS, Vajpayee RB. Intrascleral fibrin glue intraocular lens fixation combined with Descemet-stripping automated endothelial keratoplasty or penetrating keratoplasty. J Cataract Refract Surg 2012;38(7):1240-1245

7 Faia LJ, Wolfe JD, Williams GA. Sutureless scleral fixation of intraocular lenses: outcomes of two approaches. The 2014 Yasuo Tano Memorial Lecture. Graefe's Arch Clin Exp Ophthamology 2015;253(1):1-5

8 Peng RM, Guo YX, Qiu Y, Hao YS, Hong J. Complications and outcomes of descemet stripping automated endothelial keratoplasty with artisan aphakia intraocular lens implantation. Int J Ophthalmol 2018;11(4):607-611

9 Shah AK, Terry MA, Shamie N, et al. Complications and clinical outcomes of descemet stripping automated endothelial keratoplasty with intraocular lens exchange. Am J Ophthalmol 2010;149(3):390-7.e1

10 Vanathi M, Sharma N, Sinha R, Tandon R, Titiyal JS, Vajpayee RB.BMCophthalmology.BMCOphthalmol2005;5:1-5

11 Sugar A. An analysis of corneal endothelial and graft survival in pseudophakic bullous keratopathy. Trans Am Ophthalmol Soc 1989;87:762-801

12 Gonçalves ED, Campos M, Paris F, Gomes JAP, Farias CC. Bullous keratopathy: etiopathogenesis and treatment [in Portugese]. Arq Bras Oftalmol 2008;71(6(suppl) :61-64

13 Pricopie S, Istrate S, Voinea L, Leasu C, Paun V, Radu C. Pseudophakic bullous keratopathy. Rom J Ophthalmol 2017; 61(2):90-94

14 Ousley PJ, Terry MA. Stability of vision, topography, and endothelial cell density from 1 year to 2 years after deep lamellar endothelial keratoplasty surgery. Ophthalmology 2005;112(1):50-57

15 Le R, Yucel N, Khattak S, Yucel YH, Prud'homme GJ, Gupta N. Current indications and surgical approaches to corneal transplants at the University of Toronto: A clinical-pathological study. Can J Ophthalmol 2017;52(1):74-79

16 Keenan TDL, Jones MNA, Rushton S, Carley FM; National Health Service Blood and Transplant Ocular Tissue Advisory Group and Contributing Ophthalmologists (Ocular Tissue Advisory Group Audit Study 8). Trends in the indications for corneal 
graft surgery in the United Kingdom: 1999 through 2009. Arch Ophthalmol 2012;130(5):621-628

17 Tan JCHHolland SP, Dubord PJ, Moloney G, McCarthy M, Yeung SN. Evolving indications for and trends in keratoplasty in British Canada, from 2002 to 2011: a 10-year review. 2014;33(3):252-256

18 Zare M, Javadi MA, Einollahi B, et al. Changing indications and surgical techniques for corneal transplantation between 2004 and 2009 at a tertiary referral center. Middle East Afr J Ophthalmol 2012;19(3):323-329

19 Cunningham WJ, Brookes NH, Twohill HC, et al. Trends in the distribution of donor corneal tissue and indications for corneal transplantation: the New Zealand National Eye Bank Study 2000-2009. Clin Exp Ophthalmol 2012;40(2):141-147

20 Wylegala E, Tarnawska D. Management of pseudophakic bullous keratopathy by combined Descemet- stripping endothelial keratoplasty and intraocular lens exchange. J Cataract Refract Surg 2008;34(10):1708-1714

21 Terry MA, Wall JM, Hoar KL, Ousley PJ. A prospective study of endothelial cell loss during the 2 years after deep lamellar endothelial keratoplasty. Ophthalmology 2007;114(4):631-639

22 Vajpayee RB, Maharana PK, Jain S, Sharma N, Jhanji V. Thin lenticule Descemet's stripping automated endothelial keratoplasty: single, slow pass technique. Clin Exp Ophthalmol 2014;42(5):411-416

23 Terry MA, Shamie N, Chen ES, Hoar KL, Friend DJ. Endothelial keratoplasty a simplified technique to minimize graft dislocation, iatrogenic graft failure, and pupillary block. Ophthalmology 2008;115(7):1179-1186

24 Price MO, Price FW Jr. Descemet's stripping with endothelial keratoplasty: comparative outcomes with microkeratome-dissected and manually dissected donor tissue. Ophthalmology 2006;113(11):1936-1942

25 Dooren BT, Saelens IEY, Bleyen I, Mulder PGH, Bartels MC, Rij GV. Endothelial cell decay after descemet's stripping automated endothelial keratoplasty and top hat penetrating keratoplasty. Invest Ophthalmol Vis Sci 2011;52(12):9226-9231

26 Dick HB, Augustin AJ. Lens implant selection with absence of capsular support. Curr Opin Ophthalmol 2001;12(1):47-57

27 Stem MS, Todorich B, Woodward MA, Hsu J, Wolfe D. Scleral-fixated intraocular lenses: past and present. J Vitreoretin Dis 2017;1(2):144-152
28 Kumar DA, Agarwal A, Agarwal A, Prakash G, Jacob S. Glued intraocular lens implantation for eyes with defective capsules: a retrospective analysis of anatomical and functional outcome. Saudi J Ophthalmol 2011;25(3):245-254

29 Gabor SGB, Pavlidis MM. Sutureless intrascleral posterior chamber intraocular lens fixation. J Cataract Refract Surg 2007;33(11):1851-1854

30 Hannush SB. Sutured posterior chamber intraocular lenses: indications and procedure. Curr Opin Ophthalmol 2000;11(4):233-240

31 Brunette I, Stulting RD, Rinne JR, Iii GOW, Gemmil M. Penetrating keratoplasty with anterior and posterior chamber intraocular lens implantation. Arch Ophthalmol 2015

32 Koenig SBDupps WJ, Jr. Covert DJ, Meisler DM. Simple technique to unfold the donor corneal lenticule during Descemet's stripping and automated endothelial keratoplasty. 2007;33(2):189-190

33 Mearza AA, Qureshi MA, Rostron CK. Experience and 12-month results of descemet-stripping endothelial keratoplasty (DSEK) with a small-incision technique. Cornea 2007;26(3):279-283

34 Melles GR, Wijdh RH, Nieuwendaal CP. A technique to excise the descemet membrane from a recipient cornea (descemetorhexis. Cornea 2004;23(3):286-288

35 Sindal MD, Nakhwa CP, Sengupta S. Comparison of sutured versus sutureless scleral-fixated intraocular lenses. J Cataract Refract Surg 2016;42(1):27-34

36 Marianelli BF, Mendes TS, Manzano, RP de. Observational study of intraocular lens tilt in sutureless intrascleral fixation versus standard transscleral suture fixation determined by ultrasound biomicroscopy. Int J Retin Vitr 2019;5-33

37 Lee JG, Lee JH, Chung H. Factors contributing to retinal detachment after transscleral fixation of posterior chamber intraocular lenses. J Cataract Refract Surg 1998;24(5):697-702

38 Solomon K, Gussler JR, Gussler C. Van Meter WS. Incidence and management of complications of transsclerally sutured posterior chamber lenses. J Cataract Refract Surg 1993; 19(4):488-493

39 Parekh P, Green WR, Stark WJ, Akpek EK. Subluxation of suture-fixated posterior chamber intraocular lenses a clinicopathologic study. Ophthalmology 2007;114(2):232-237 